\title{
N89-12587
}

\section{CORRELATION STUDIES ON SURFACE PARTICLE DETECTION METHODS*}

\author{
Ronald V. Peterson and James C. White \\ Hughes Aircraft Company
}

\section{ABSTRACT}

The accurate determination of dust levels on optical surfaces is necessary to assess sensor system performance. A comparison study was made on several particle measurement methods including those based on direct imaging and light scattering. The effectiveness of removing the particles from the surface prior to determining particle size distributions was also assessed.

These studies revealed that some methods, especially those requiring particle removal before analysis, are subject to large systematic errors affecting particle size distributions. Thus, an understanding of the particle measurement methods employed is necessary before any surface cleanliness or obstruction value assignments are accepted as true representation of an optical surface contamination condition.

\section{INTRODUCTION}

Since the advent of optical and other contamination sensitive systems on board spacecraft, there has been a concern that particulate and molecular contamination would compromise the performance during the lifetime of the spacecraft. These concerns are not unfounded as decreased performance in some recent spacecraft has been attributed to contamination.

As the demand for greater cleanliness levels increases due to the higher performance requirements, so does the need to develop more sensitive, reliable methods for the measurement of surface particlate contamination.

In a previous SPIE paper ${ }^{1}$ the current particle detection/analysis methods for spacecraft surfaces were discussed. Methods included detection and analysis of

* This work was performed under contract No. F20602-85-C-0279, For the Air Force Systems Command, Rome Air Development Center, Griffis Air Force Base 
particles directly on a surface, as well as those that require the removal of particles from the surface in order to perform the analysis. In certain instances the goemetry of the hardware may dictate that particles be removed for effective particle measurement.

In this paper, correlation studies will be discussed on work performed on some of these methods. The correlations were done by analyzing the same or similar sample populations with the different methods. Particle distributions were obtained and plotted in terms of cleanliness levels and obscuration or covering fraction (CF) values. Bidirectional reflectance distribution function (BRDF) scatter was also measured on some samples and compared with particle counting methods.

\section{SAMPLE WITNESS PLATES}

Several sample witness plates were selected for use in the correlation study. These are listed in Table I. They were selected on the basis of optical materials used in spacecraft and witness samples typically used in monitoring cleanliness levels during spacecraft ground operations.

Table I Sample Witness P1ates for Dust Fallout

\begin{tabular}{|c|c|}
\hline $\begin{array}{l}\text { Aluminum Mirrors on Glass Substrate } \\
\text { with SiOx Overcoat (CLM) }\end{array}$ & $\begin{array}{l}1 \times 1 \text { inch } \\
6 \times 6 \text { inch }\end{array}$ \\
\hline $\begin{array}{l}\text { Polished Glass } \\
\text { (CLBG) } \\
\text { (DMC) }\end{array}$ & $\begin{array}{lllll}1 & x & 1 & \text { inch black } \\
6 & \times & 6 & \text { inch black } \\
3 & \times & 3 & \text { inch } & \text { clear }\end{array}$ \\
\hline $\begin{array}{l}\text { Fi1ter Paper } \\
\text { (CLF) }\end{array}$ & $\begin{array}{c}47 \mathrm{~mm} \text { Diameter Millipore } \\
\text { Grided }\end{array}$ \\
\hline
\end{tabular}

\section{PARTICLE POPULATION MEDIA}

The sample witness plates were populated with particle fallout from a laboratory environment. The laborafory fallout, collected over a period of days, roughly followed a Mil-Std $1246 \mathrm{~A}^{2}$ distribution with fewer particles detected below $10 \mu \mathrm{m}$ and more detected above $50 \mu \mathrm{m}$ than would be expected from the $1246 \mathrm{~A}$ idealized distribution. 
The particle detection/analysis methods listed in Table II were used in the correlation study. The methods tested included direct measurement of the witness samples such as photography, microscopy, and light scattering and an indirect method which involved a solvent flush of the surface to remove the particles with subsequent particle analysis by microscopy or automatic particle counting.

TABLE II Particle Detection/Analysis Methods Used in Correlation Study

\begin{tabular}{ll}
\hline & \multicolumn{1}{c}{ SAMPLE TYPE } \\
\cline { 2 - 2 } Stereo Optical Microscopy & $\begin{array}{l}\text { Fallout and rinses collected on } \\
\text { Filter Paper }\end{array}$ \\
Optical Microscopy & $\begin{array}{l}\text { Fallout and rinses collected } \\
\text { on Filter Paper }\end{array}$ \\
Photography & Mirror and Glass Samples \\
BRDF Scatter & Mirror and Glass Samples \\
Automatic Particle Counter & $\begin{array}{l}\text { Rinses from Mirror \& Glass } \\
\text { Samples }\end{array}$ \\
\hline
\end{tabular}

Following population of the witness sample with laboratory fallout, the samples were analyzed utilizing the scheme in Table III.

\section{DESCRIPTION OF METHODS}

\section{OPTICAL MICROSCOPY}

Optical microscopy is a standard method used to count particles on substrates. It is most effective on grided filter paper where particle populations can be counted within defined areas. Two optical microscopy methods were used to count particles. One, using a light microscope with oblique lighting, follows the ASTM F312 method. Particles are observed at $100 \mathrm{x}$ for the smaller size particles and $40 \mathrm{x}$ for the larger ones. The second method, developed in the Hughes Contamination Physics Laboratory of the Optical Technology Department, uses a stereo microscope with grazing incident lighting of the sample surface. Magnification is about 70 .

The two microscope methods were compared as part of this correlation study. 


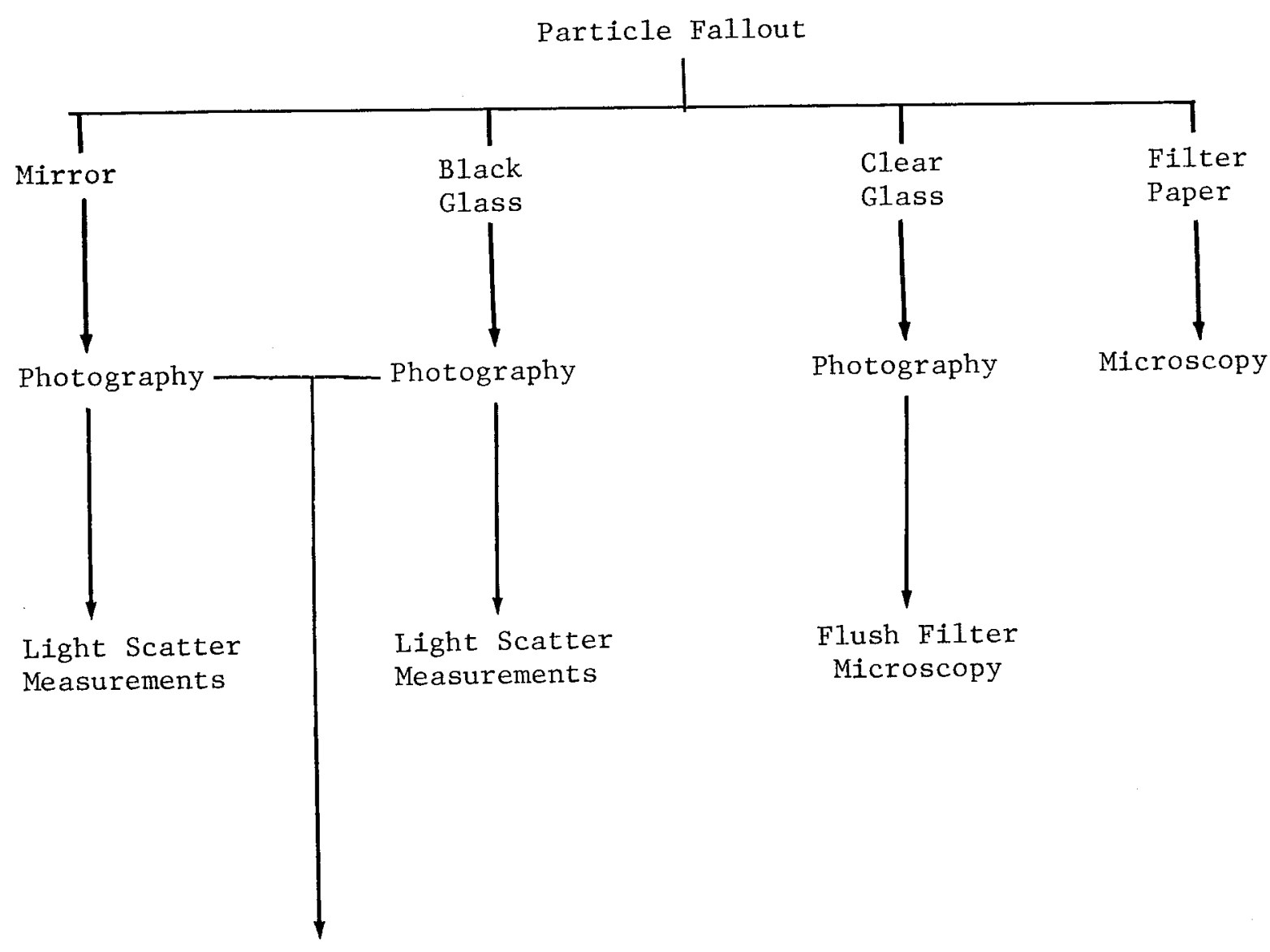

Flush, Filter Microscopy

or

Flush, Automatic Particle Counting 


\section{PHOTOGRAPHIC/CAMERA METHOD}

The photographic/camera system used in the Hughes contamination Physics Laboratory has a Polaroid enlargement camera equipped with a MD-4 shutter and a Nikkon 55MM macrolens. Photographs of particles on mirror or glass surfaces are taken at a magnification of 10 on Polaroid type 55 film giving a 0.4 by 0.45 inch frame. The developed negative is projected onto a grided surface and the particles sized and counted at an overall magnification of 100 .

\section{BIDIRECTIONAL REFLECTANCE DISTRIBUTION FUNCTION (BRDF) SCATTER}

$B R D F$ is an optical function which describes the scattering properties of a surface. Scattering is due to surface irregularities or imperfections as well as contamination. Contamination will scatter part of the incident radiation with an intensity which depends on direction. BRDF is obtained from the quantification of the spatial distribution of the scattered energy.

The Hughes Optical Technology Scatterometer Laboratory has the capability of measuring BRDF on various size and configured mirror and glass witness plates and optical components at several wavelengths including $351.1,514.5,632.8 \mathrm{~nm}$ and 1.06 , 3.39 and $10.6 \mu \mathrm{m}$. Surface cleanliness levels and covering fraction or obscuration values are related to the BRDF measurements and the particle measurements were used to study and correlate the relationship.

\section{SURFACE FLUSH METHODS}

A standard method for evaluating hardware cleanliness calls for flushing the surface with solvent to remove the particles, then filtering and counting the particles on the filter paper using a light microscope. This method is widely used in the spacecraft contamination community to ascertain and monitor hardware cleanliness levels. This method was followed to provide data on particle populations on glass and mirror surfaces following flushing.

The surface flush method is also used to obtain samples for measurement in the liquid particle counter. In this case the solvent flush is directly measured in the automatic counter.

Approximately $100 \mathrm{ml}$ of filtered IPA solvent under 25 PSI pressure was directed onto the sample surface and thoroughly flushed. The collected solvent flush was filtered for microscopic analysis of the particles on the filter or measured directly in the liquid particle counter/analyzer.

\section{LIQUID PARTICLE COUNTER}

The liquid particle counter works on the principle of light scattering from particles. Light from a source (generally a laser) passes through a known volume of liquid and the scattered light from the particles in the moving fluid are collected on a detector and recorded in intensity bins which relate to particle size (area).

A serious problem with these instruments is that of diminishing sensitivity to larger particles $(>25 \mu \mathrm{m})$ and those that have similar indices of refraction as the 
fluid system.

Bubbles in the sample fluid are also a problem in that they are counted as particles. A pure prefiltered bubble-free fluid must be used as a carrier, otherwise very high particle backgrounds will be encountered.

The automatic counter used in this study was a HiAC/Rayco mode1 4100.

\section{CONTAMINATION OF WITNESS SAMPLES}

Three experiments were performed for the purpose of collecting laboratory fallout samples.

The experimental conditions, witness sample types and particle analysis methods used are shown in Table IV.

The three experiments or data sets from laboratory fallout were taken by placing the witness samples plates and filter papers on top of a wall cabinet in one of our laboratories. The 400 square foot room has filtered inlet air flowing from ceiling ducts. The working laboratory is not classified as a clean room.

\section{PRESENTATION OF DATA}

The particles imaged using the photography and microscopy methods were manually counted and placed into size bins according to their particle diameter. The size bins chosen were 5-10, 11-25, 26-50, 51-100, 100 and 200 (fibers) $\mu \mathrm{m}$. The counting procedure for the two methods was thus standardized and the obscuration or covering fraction values and cleanliness levels were calculated from this data.

This obscuration or covering fraction data were obtained from the particle size distributions by multiplying the average area (from the mean diameter in the bin) by the total number of particles in a bin. All the particle areas in the bins were summed to give a total particle area which is then expressed as a fraction of the total area sampled.

Mil-Std 1246A defines the product cleanliness leve1s on the basis of the number of particles of given size on a surface per square foot. The number of particles per square foot of surface, for all particles of the specified size and larger, plot as a straight line on the $\log$ vs. $\log ^{2}$ scales as shown in Figure 1. The particulate cleanliness level is defined by the line crossing the abscissa.

The particle size data from microscopy and photography were plotted on the $1246 \mathrm{~A}$ format to compare cleanliness level for the different fallouts and analysis methods. Data from the surface flushed samples were treated in an identical manner as the photography and microscopy data.

The light scatter data is reported as total integrated scatter (TIS) over a 2 to $60^{\circ}$ scattering angle. Laser light $(514.5 \mathrm{~nm})$ is incident upon the sample at $5^{\circ}$ off the normal. The BRDF data is discussed in a later section. 


\begin{tabular}{|c|c|c|c|}
\hline Exposure Time & Sample No. & Substrate & Ana1yses \\
\hline \multicolumn{4}{|c|}{ Experiment No. 1} \\
\hline 10 Days & $\begin{array}{l}\text { CL1 } \\
\text { CL2 } \\
\text { CL6M1 }\end{array}$ & $\begin{array}{l}\text { A1 Mirror } \\
\text { Black Glass } \\
6 \times 6 " \text { A1 Mirror }\end{array}$ & $\begin{array}{l}\text { P, LS } \\
\text { P, LS } \\
\text { FFLM, FPC }\end{array}$ \\
\hline \multicolumn{4}{|c|}{ Experiment No. $2 \mathrm{~A}$} \\
\hline 7 Days & $\begin{array}{l}\text { CLM3 } \\
\text { CLBG3 } \\
\text { DMC }\end{array}$ & $\begin{array}{l}\text { A1 Mirror } \\
\text { Black Glass } \\
3 \times 3^{\prime \prime} \text { Clear Glass }\end{array}$ & $\begin{array}{l}\mathrm{P} \\
\mathrm{P} \\
\mathrm{P}\end{array}$ \\
\hline \multicolumn{4}{|c|}{ Experiment No. 2B } \\
\hline 12 Days & $\begin{array}{l}\text { CLM3 } \\
\text { CLBG3 } \\
\text { DMC }\end{array}$ & $\begin{array}{l}\text { A1 Mirror } \\
\text { Black Glass } \\
3 \times 3^{\prime \prime} \text { Clear Glass }\end{array}$ & $\begin{array}{l}\mathrm{P} \\
\mathrm{P} \\
\mathrm{P}\end{array}$ \\
\hline \multicolumn{4}{|c|}{ Experiment No. 2C } \\
\hline 15 Days & $\begin{array}{l}\text { CLM3 } \\
\text { CLM4 } \\
\text { CLBG3 } \\
\text { CL6BG1 } \\
\text { DMC } \\
\text { CLF2 } \\
\text { CLF3 }\end{array}$ & $\begin{array}{l}\text { A1 Mirror } \\
\text { A1 Mirror } \\
\text { B1ack Glass } \\
6 \text { x 6" Black Glass } \\
3 \times 3 " \text { Clear Glass } \\
\text { Filter Paper } \\
\text { Filter Paper }\end{array}$ & $\begin{array}{l}\text { P, LS } \\
\text { P, LS } \\
\text { P, LS } \\
\text { P, FFLM, FPC } \\
\text { P, FPC } \\
\text { LM } \\
\text { LM, SM }\end{array}$ \\
\hline \multicolumn{4}{|c|}{ Experiment No. 3} \\
\hline 7 Days & $\begin{array}{l}\text { CL2M1 } \\
\text { CL2BG1 } \\
\text { DMC } \\
\text { CLF20 }\end{array}$ & $\begin{array}{l}2 \times 2^{\prime \prime} \text { A1 Mirror } \\
2 \times 2^{\prime \prime} \text { Black Glass } \\
3 \times 3^{\prime \prime} \text { Clear Glass } \\
\text { Filter Paper }\end{array}$ & $\begin{array}{l}\mathrm{P}, \mathrm{LS} \\
\mathrm{P}, \mathrm{LS} \\
\mathrm{P} \\
\mathrm{SM}\end{array}$ \\
\hline
\end{tabular}

Analysis Symbols

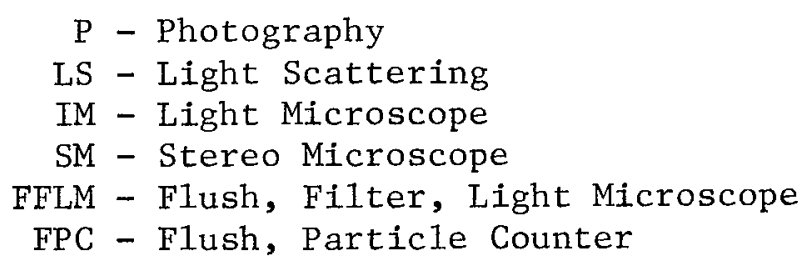


RESULTS

LABORATORY FALLOUT

The initial laboratory fallout experiment consisted of exposure of two mirrors and a black glass substrate to 10 days fallout. The results of the particle analyses are shown in Table $V$ where the obscuration or covering fraction (CF) values have been calculated from the particle size distributions. Light scatter (TIS) data was obtained on one sample. It can be immediately seen that the flush, filter, microscopy and the flush, automatic particle counter methods give dramatically lower CF values that those obtained by the photography method.

TABLE V Laboratory Fallout - Experiment 1 - 10 days

\begin{tabular}{|c|c|c|c|}
\hline Sample & $\begin{array}{l}\text { Method of } \\
\text { Analysis }\end{array}$ & $\begin{array}{l}\% \text { Covering } \\
\text { Fraction }\end{array}$ & $\begin{array}{c}\text { Total Integrated } \\
\text { Scatter }\end{array}$ \\
\hline CL1AL & Photography & 0.18 & $2.65 \times 10^{-3}$ \\
\hline CLIBG & Photography & 0.2 & \\
\hline \multirow[t]{3}{*}{ CL6M1 } & Photography & 0.35 & \\
\hline & $\begin{array}{l}\text { Flush, Filter, } \\
\text { Microscopy }\end{array}$ & 0.012 & \\
\hline & $\begin{array}{l}\text { Flush, Automatic } \\
\text { Particle Counter }\end{array}$ & 0.008 & \\
\hline
\end{tabular}

Figure 2 shows plots of cleanliness levels obtained from the particle analysis data. The top curve is from the photography measurements on the $6 \times 6$ inch aluminum mirror. The other two curves represent data obtained from flushing and analyzing the particles from the surface of the mirror following photography. Half of the flush was filtered and the particle counted using optical microscopy. The other half of the flush was analyzed using the liquid automatic particle counter. All particle distributions were normalized to a one square foot area for presentation with the $1246 \mathrm{~A}$ curves. The brackets represent photographic data from a 1 × 1 inch mirror and a 1 x 1 inch black glass sample that were exposed simultaneously with the large mirror.

While the photographic method gives reasonable correlation with the idealized $1246 \mathrm{~A}$ curves in the inid particle sizes, the flush and analysis methods give large departures from the idealized curves and, of course, the photography measurements.

The photography method shows the cleanliness level at about $600-700$ and $\mathrm{CF}$ (covering fraction) of about 0.2 to $0.3 \%$. The flush/microscopy method gave a cleanliness level of about 300 and only about $0.01 \% \mathrm{CF}$. Thus, if the flush data were to be believed, a component or the optical sample would pass as clean 
when, in fact, the samples even appear dirty.

The CF and TIS data obtained from particle analysis samples exposed in experiment 2 is shown in Table VI. The data shows an increase in the number of particles (CF) with lengthening exposure to the lab environment as would be expected.

The total integrated scatter (TIS) and the covering fraction data show good agreement for laboratory fallout. The black glass data, however, reveal about an order of magnitude less TIS for a given covering fraction, due to absorption of scattered light by the black glass. Figure 3 is the cleanliness data from the 15 day experiment (Exp, 2C). The data show an increase in the number of particles (CF) with lenthening exposure to the lab environment as would be expected. There is good agreement between particle distribution obtained on the mirror and the black glass samples. The photographic results results from the glass plate (DMC) showed fewer particles but were in reasonable agreement with the CLM3 and CLBG3 particle size distributions.

The cleanliness levels plots of microscopy measurements from the filter paper exposed to the fallout are shown in Figure 4. The CF and cleanliness levels show that fewer particles were collected or observed on the filter papers than on the mirrors and blackglass. It can be seen from Figure 4 that the light microscope (ASTM methods)cleanliness level was lower (showed fewer particles) than the stereo method with grazing incident light. This was especially evident at the smaller particle region of the graph. This difference was attributed to the difficulty associated with seeing particles that are not properly illuminated. Grazing incident light is much superior to light illumination at $45^{\circ}$ to the surface when observing small particles on a surface because it results in better optical contrast.

Even with grazing incident light (and also the photographic method) the particle population drops off from the $1246 \mathrm{~A}$ idealized curve as the particle size drops below 25um. While it may be true that there are fewer particles falling out below 25um than would be suggested by the idealized curves, some or most of the tailoff is probably due to increasing difficulty in observing smaller particles.

The increase in particle population in the large particle sized that would be expected (from 1246A) is likely a result of man-generated particles and fibers from activities inside the room that are not expected in idealized situations but very much expected in real situations! Few particles are counted in the large-size region (above $100 \mu \mathrm{m}$ ) and, therefore, are not considered to be statistically representative.

When the method of particle analysis involved the removal of particles using a solvent flush an even more dramatic decrease in particle population was noted as can be seen in Table VI and Figure 5. These results corroborate the results obtained from Experiment 1 where the solvent flush method also gave unreasonable $\mathrm{CF}$ and cleanliness levels from the contaminated samples.

The data showed that rinsing does not effectively remove all particles from a surface and that low values of particle concentration can be expected when this method is employed. It appears from the data that the larger particles are more efficiently removed by flushing that the smaller particles. Rinsing a surface, filtering the rinse and microscopic evaluation does not give good results, however, rinsing, followed by liquid particle counting is even worse as the results in Figures 2 and 5 reveal. 
TABLE VI

Laboratory Fallout - Experiment 2

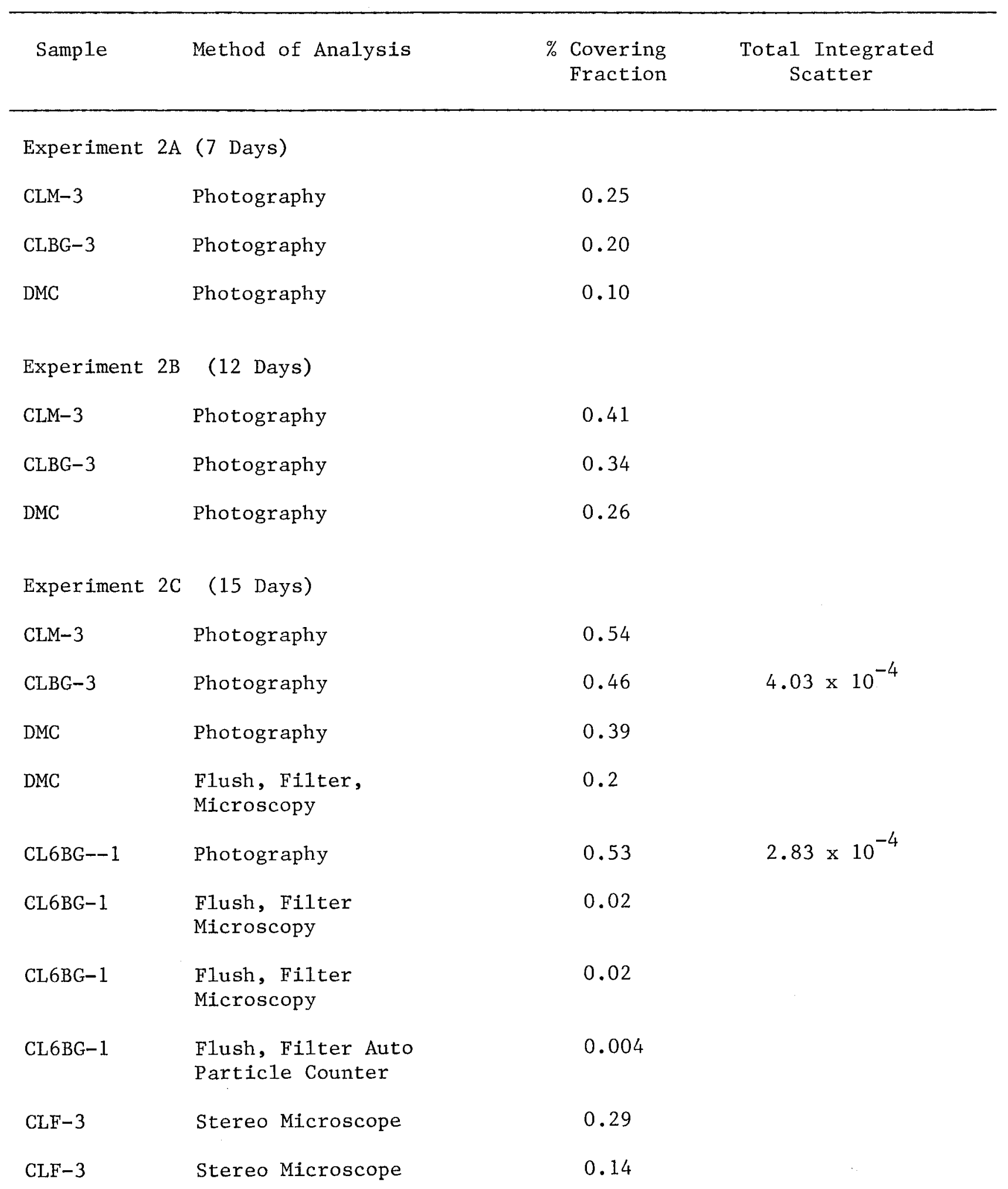


A Hiac/Royco automatic particle counter was used to measure the particle size distribution in one-half the rinse from CL6BG1. The small and large particle sizes are extremely low compared to the photographic and microscopic methods. This is attributed to the rinse not efficiently removing the sma11 particles and the analyzer being insensitive to the larger $(>20 \mu \mathrm{m})$ particles.

Data from experiment 3 is shown in TABLE VII.

These data verify what was found in the first and second experiment, namely that:

1) Photography gives particle distribution that are reasonable for the type and length of fallout.

2) The mirror and black glass samples give similar results.

3) The cleanliness level plots follow the Mil-Std 1246A in the mid particle range $(25-100 \mu \mathrm{m})$ but are lower in population in the smaller and higher in the larger particle regions than predicted in $1246 \mathrm{~A}$.

TABLE VII Laboratory Fallout - Experiment 3, 7 Days

\begin{tabular}{llcc}
\hline Sample & $\begin{array}{l}\text { Method } \\
\text { Analysis }\end{array}$ & $\begin{array}{c}\text { \% Covering } \\
\text { Fraction }\end{array}$ & $\begin{array}{c}\text { Total Integrated } \\
\text { Scatter }\end{array}$ \\
\hline CL2M1 & Photography & 0.31 & $1.67 \times 10^{-3}$ \\
CL2BG1 & Photography & 0.23 & $1.6 \times 10^{-4}$ \\
\hline
\end{tabular}

\section{LIGHT SCATTERING}

The results of the BFDF scatter measurements on the laboratory fallout samples are shown in Figures $6-8$. Figure 6 is the data from the CL2M1 and CL2BG1 samples from Experiment 3. Clean black glass and mirror samples are shown for comparison.

Black glass gives about an order magnitude less scatter than the mirror samples that were used in this study. It is interesting to see that the increase in scatter is greater at the larger scatter angles for all the contaminated samples, i.e., smaller particles are greater contributors to scatter at the larger angles.

Two samples, CLM-3 and CLBG-3 were scanned in five wavelength region for BRDF scatter. The BRDF data is presented in Figures 7 and 8 . The visible and near IR curves are similar while the mid-IR curves (3.39 and $10.6 \mu \mathrm{m})$ deviate by scattering relatively less in the high scatter angles and more in the mid-angle regions. It would be expected that the small particles would affect the high angle scatter less in the infrared due to the longer wavelength. A clean substrate background is also presented in the 15 day laboratory fallout curves. 
Several method of paritcle detection and analysis have been tested and correlated using particles from laboratory fallout. The methods included microscopy, photography, surface flush with microscopy, surface flush with liquid particle counting and BRDF scattering.

In comparing the microscopy and photographic technique it was found that photography gave somewhat higher particle counts.

The microscopy method, which genera11y gave lower counts in the less than 25um region, was improved when a stereo microscope with grazing incident light was used to illuminate the particles for viewing.

Flushing of the surface with a solvent gave lower particle populations when the filter/microscopy method was used for counting and very much lower results when automatic particle counting methods were used. Flushing does not appear to effectively remove the smaller lower particle sizes and skewed the results when plotted on a Mil-Std-1246A curve.

Laboratory fallout generally followed the $1246 \mathrm{~A}$ curve between 10 and $50 \mu \mathrm{m}$ with lower populations detected at the smaller (below $10 \mu \mathrm{m}$ ) particle sizes.

The fewer smaller particles was partially attributed to difficulty in detection of smaller particles while the higher population of large particles was attributed to normal activity in an uncontrolled (cleanliness speaking) laboratory environment.

BRFD is an effective way of detecting contamination on optical surfaces, however, the particle size distributions cannot be generated from BRDF data. The increases in BRDF were generally what was expected for the laboratory fallout. Hughes, however does have a computer program based on Mie scattering that calculates BRDF from particle populations. The predictions from this program closely matched the measured BRDF values for laboratory fallout in the visible region of the spectrum. 


\section{REFERENCES}

1. Peterson, R.V.: Detection Methods for Particles on Optical Surfaces. SPIE 30th Annual International Technical Symposium on Optical and OptoElectronic Engineering, San Diego, CA. 17-22 August 1986.

2. Mi1-STD-1246A: Military Standard Product Cleanliness Levels and Contamination Control Program. 18 August 1967. 


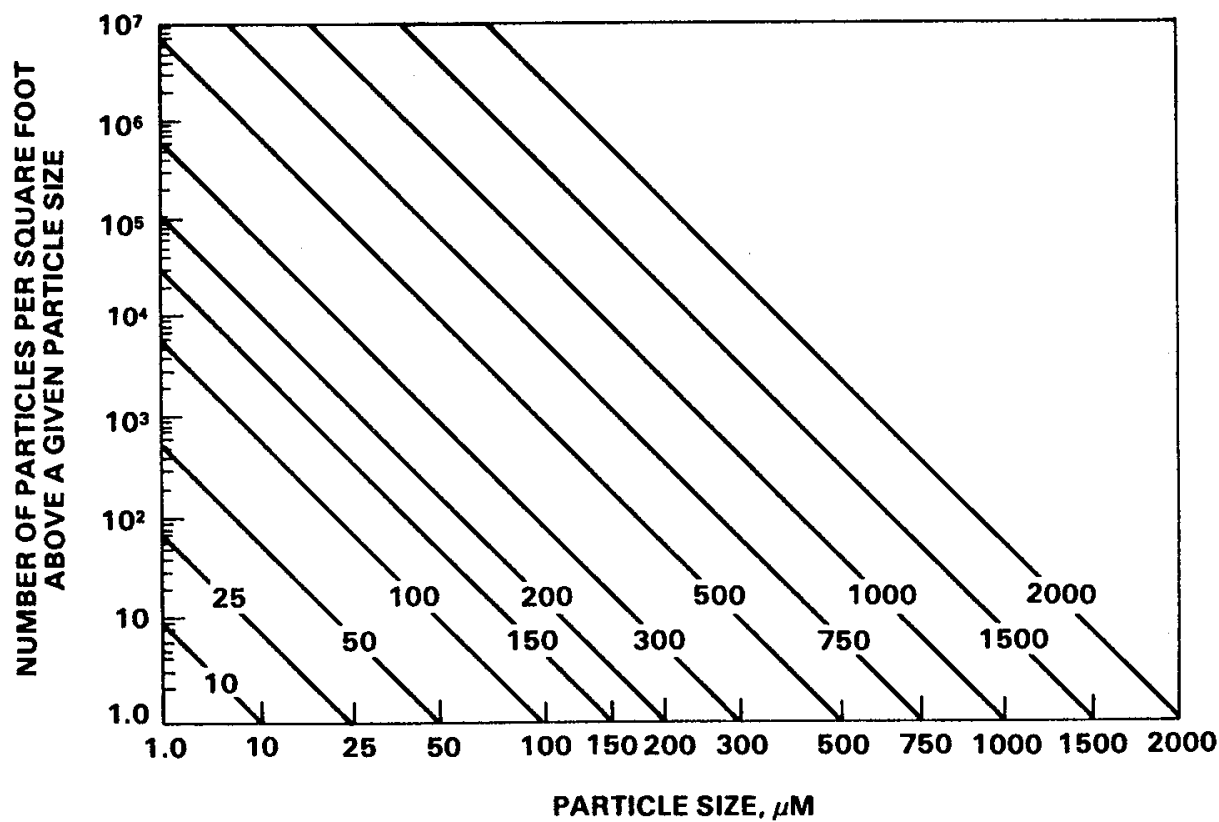

Figure 1. Product Cleanliness Levels

COMPARISON OF PHOTOGRAPHY WITH SOLVENT FLUSH METHODS

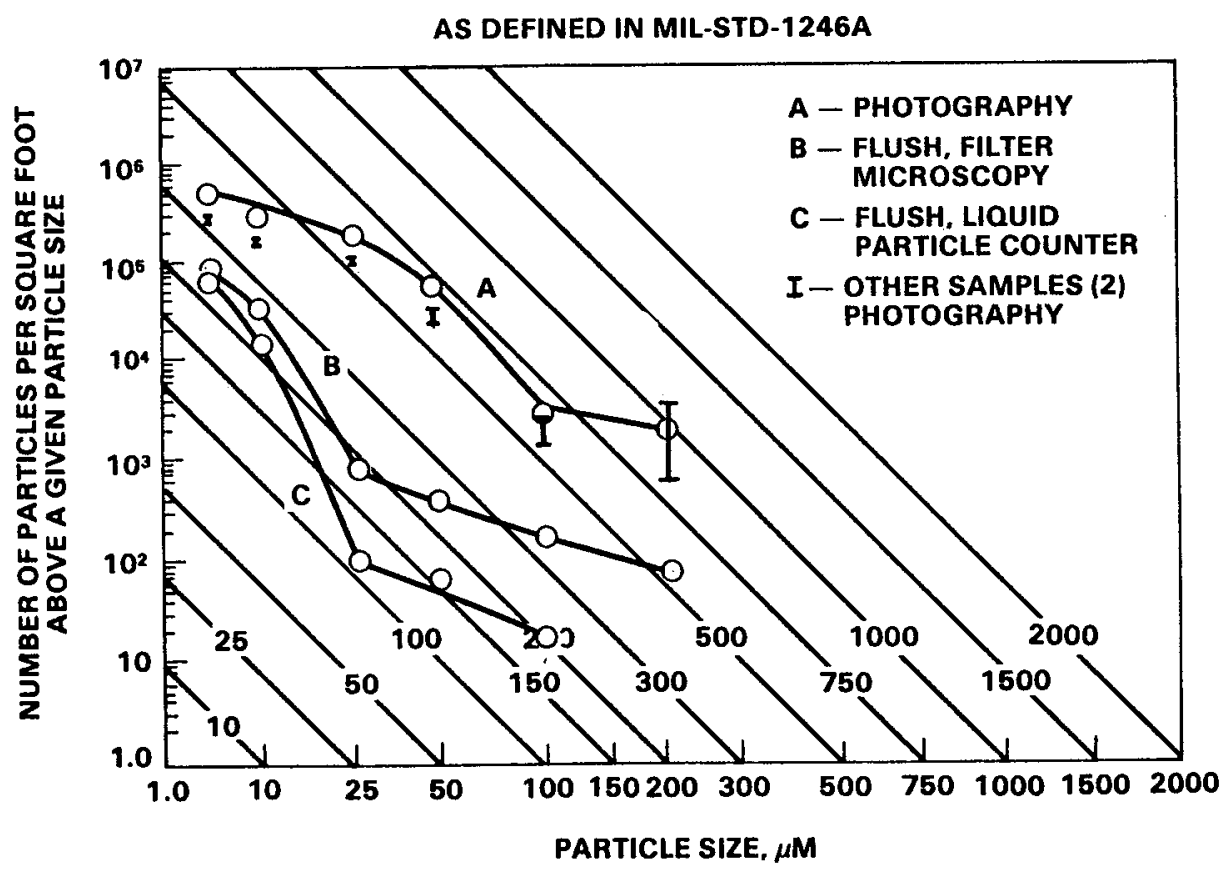

Figure 2. 10 Day Fallout Data 


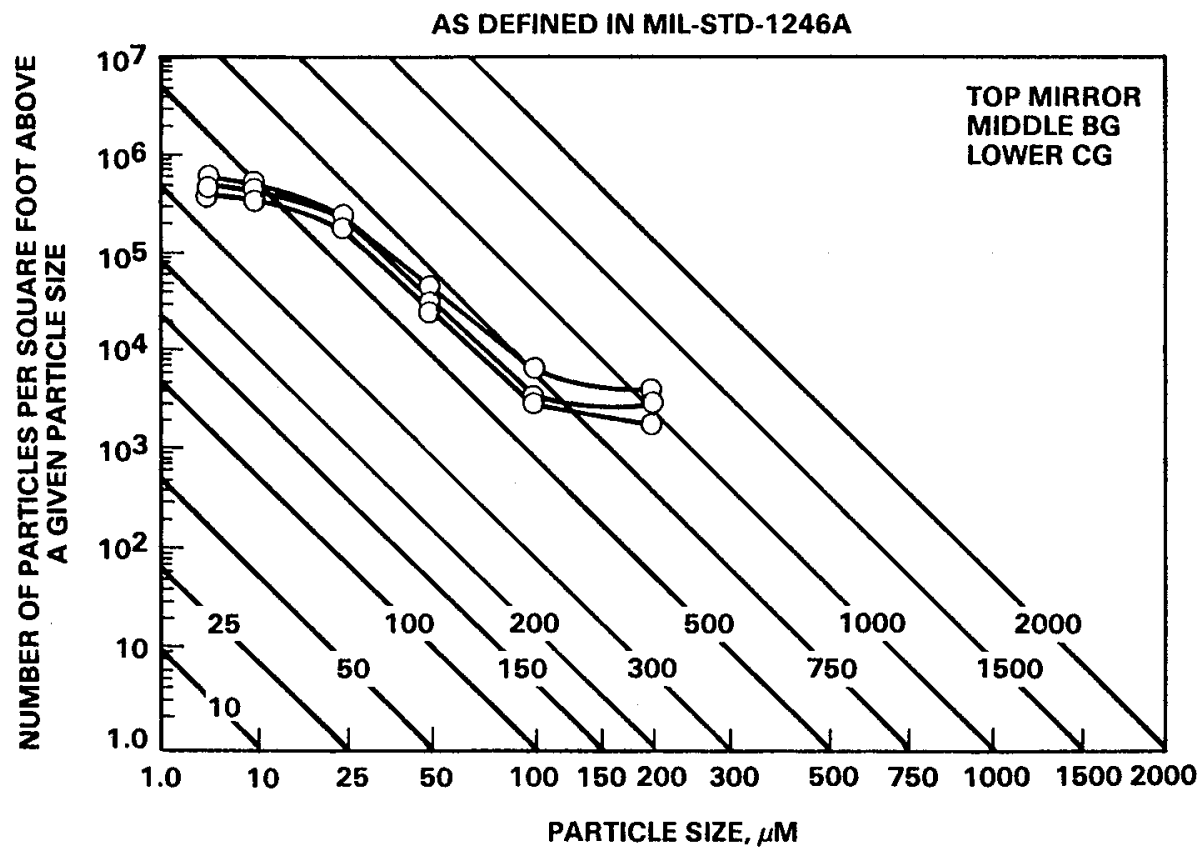

Figure 3. 15 Day Fallout Data

\section{LIGHT MICROSCOPE NOT AS EFFECTIVE AS STEREO MICROSCOPE OR PHOTOGRAPHY IN DETECTING} SMALL PARTICLES

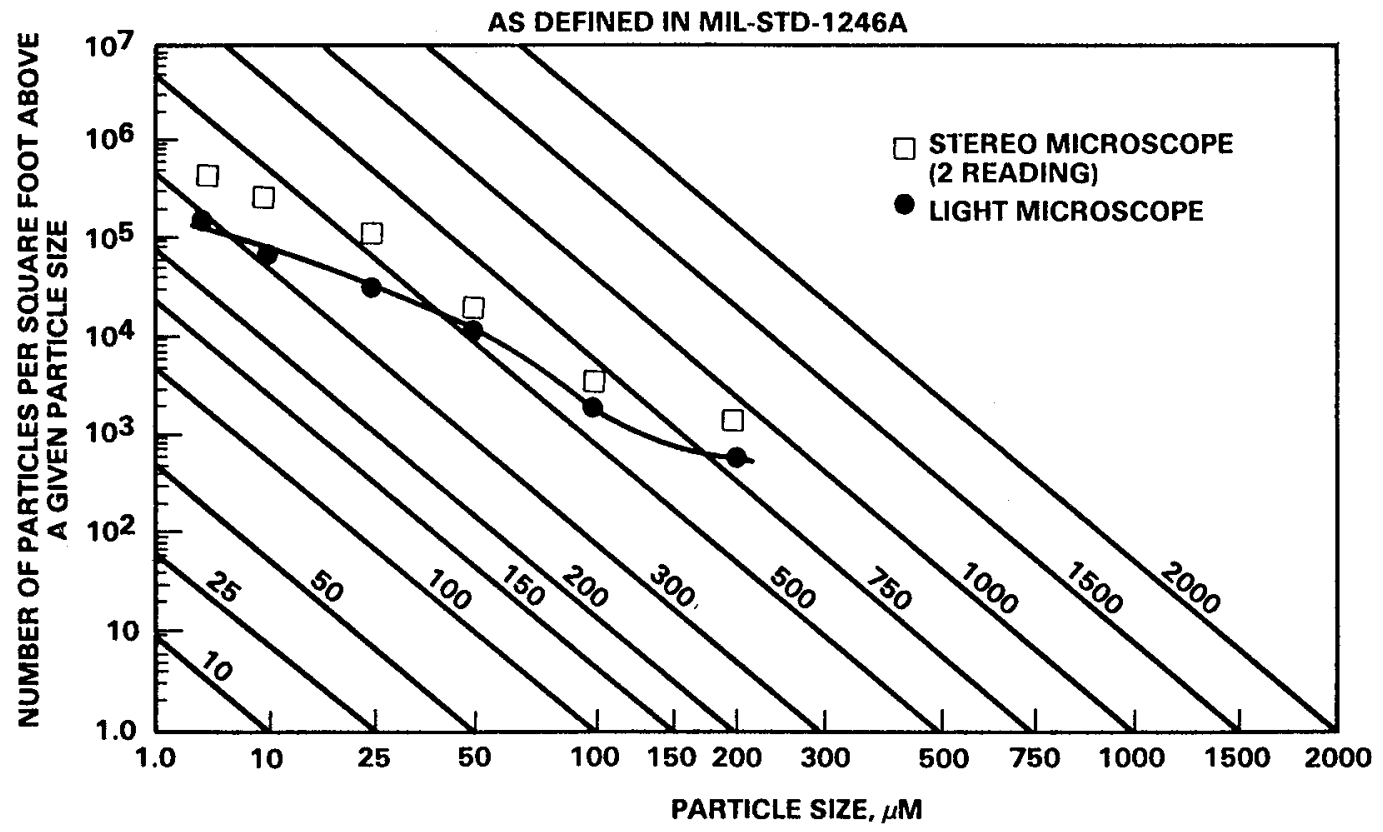

Figure 4. Comparison of Light Microscope and Stereo Microscope Particle Measurements 


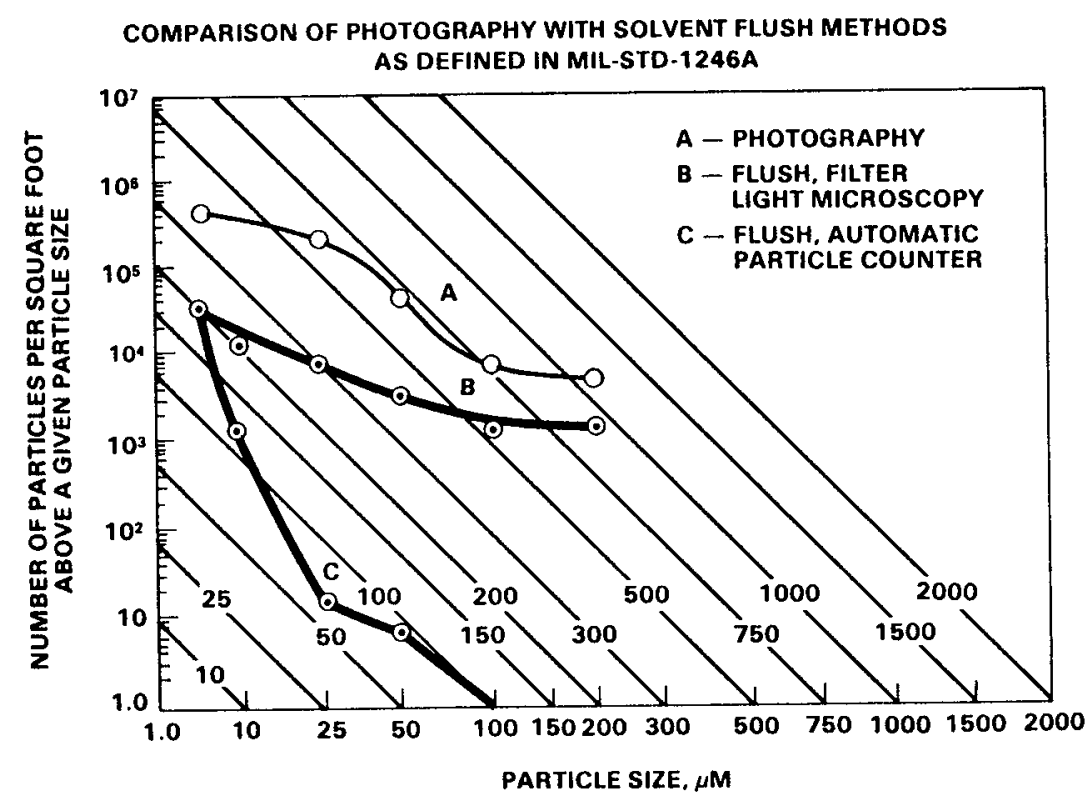

Figure 5. 15 Day Fallout Solvent Flush Data

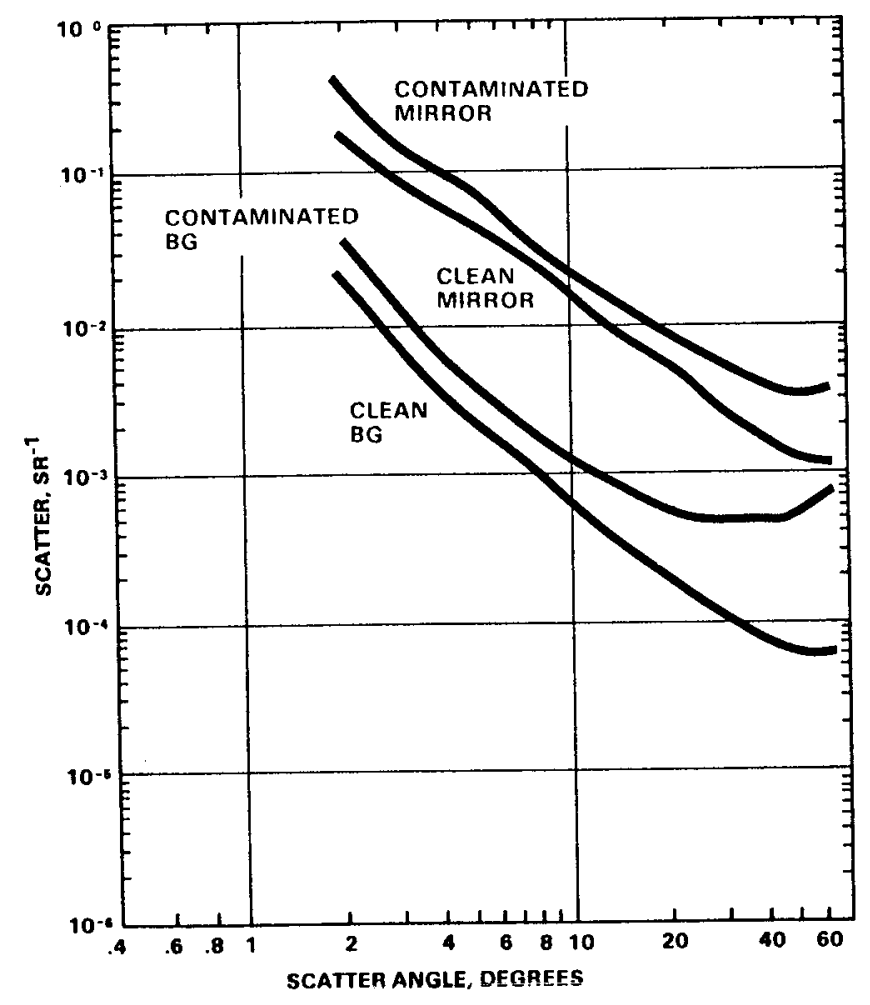

Figure 6. BRDF on CL2M1 and CL2BG1 (Exp. 3) 


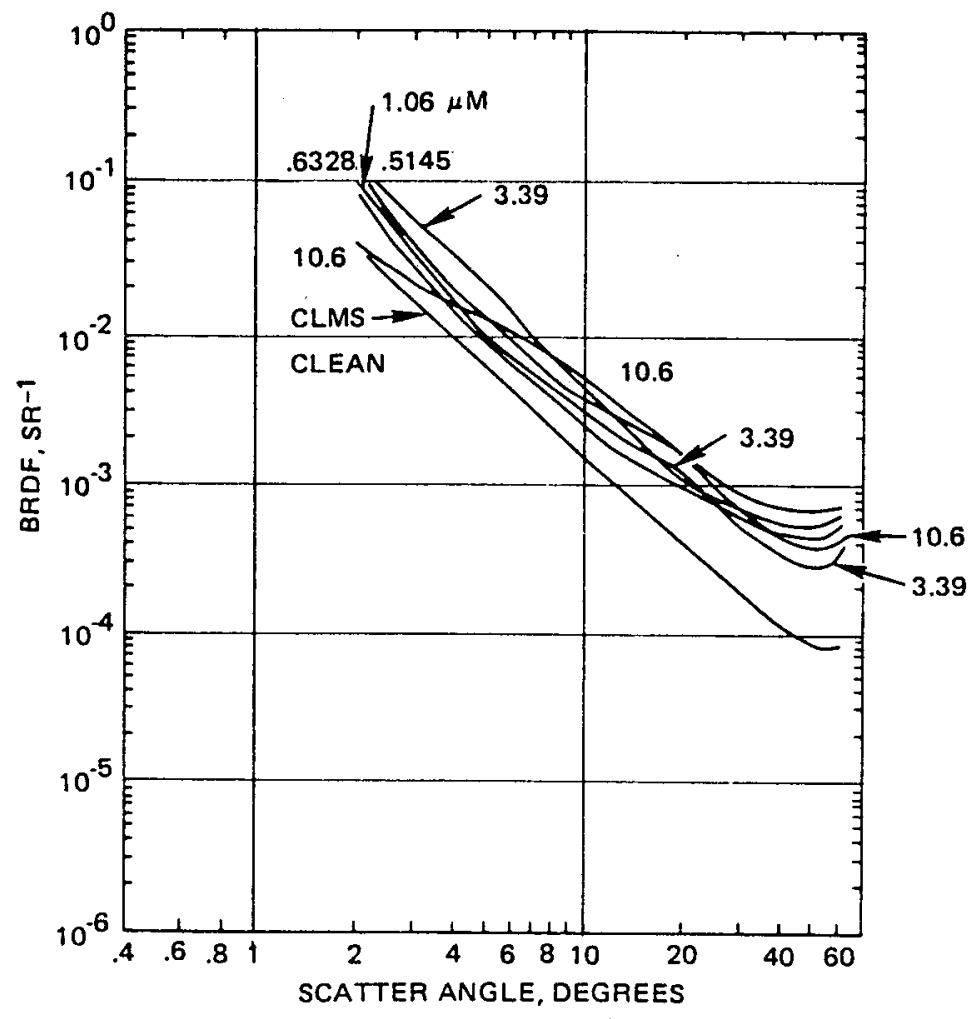

Figure 7. BRDF Measurements of CLM-3 for 5 Wavelengths

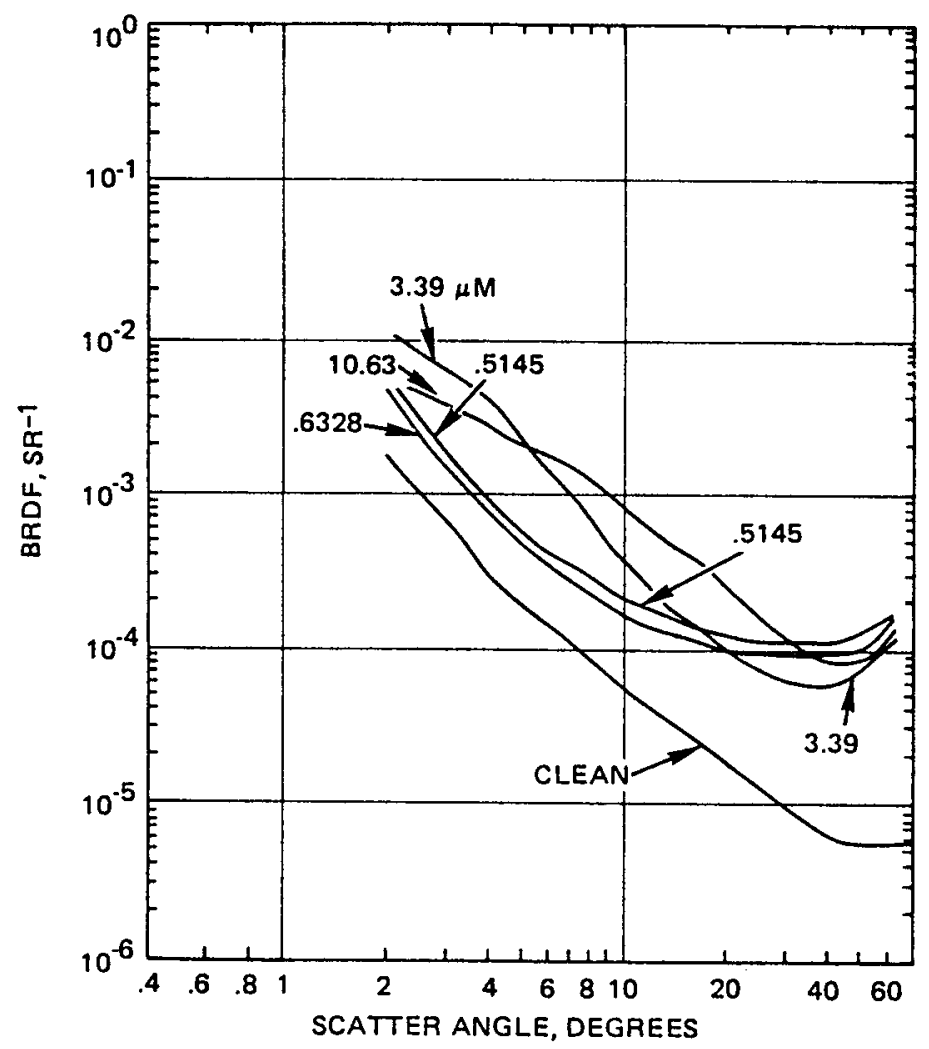

Figure 8. BRDF Measurements on CLBG-3 for 5 Wavelengths 